\title{
Stand up -komiikka ja yksilöllisyyden kaksinaisuus
}

\author{
Lectio praecursoria, 24.5.2019 Turun yliopisto.
}

\section{Antti Lindfors}

$\mathrm{P}$ sykologi Leon Rappoport (2005) mainitsee teoksessaan Punchlines: The Case of Racial, Ethnic, and Gender Humor kuulemastaan fraasista, jonka mukaan jokaisen huumorintutkijan sisällä asuu stand up -koomikko, joka pyrkii ulos. Jäin miettimään, onko asia yhtä vakava, jos on paitsi huumorintutkija, tutkii nimenomaan stand up -komiikkaa.

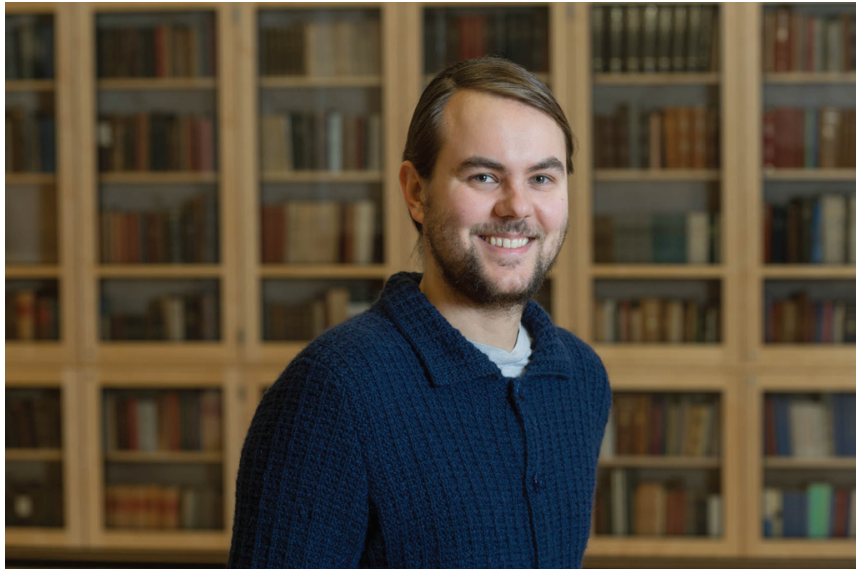

Antti Lindfors. Kuva: Philippe Gueissaz.

Median ja julkisuuden on sanottu viime vuosikymmeninä muuttaneen luonnettaan monin tavoin. Neil Postman valitteli median viihteellistymistä 80 -luvulla; sen jälkeen julkisuus on intimisoitunut eli muuttunut henkilökohtaisemmaksi, sitten performativisoitunut eli muuttunut esittävämmäksi, muuttunut dialogisemmaksi ja sosiaalisemmaksi, ja viimeisenä käänteenä: mediajulkisuus on komediallistunut. Termin commedification, siis komediallistumisen, lanseeraajien Martin Greenin ja John Swanin mukaan nykypäivän julkisuuden estetiikkaa luonnehtii keskiajan commedia dell'arteen liitetty tyyli, jota voisi nimittää sosiaalisten törmäysten spektaakkelimaiseksi leikiksi. Jos väite kuulosti vielä jokin aika sitten liioitellulta, se on vuoden 2016 marraskuusta ja eräistä tuolloin käydyistä presidentinvaaleista alkaen ollut paljon helpompi ottaa todesta.

Jos Donald Trumpia voisi jostain kiittää, häntä voisi kiittää huumorin-, komiikan- ja satiirintutkimuksen nostamisesta arvoon arvaamattomaan. Trump ei kuitenkaan ole vain loputtomien meemien ja viihdeohjelmien satiirin kohde. Vähemmälle huomiolle on ehkä jäänyt se, että Trump on myös itse retorisesti taitava nimenomaan viihdyttäjänä. Kuten antropologit Kira Hall, Donna Goldstein ja Matthew Ingram (2016) ovat näyttäneet, Trumpin menestyksen taustalla oli osaltaan hänen presidentinkampanjansa viihdearvo ja liikemiehen komedialliset kyvyt. 
Mainitut kirjoittajat luonnehtivat Trumpin kuuluisia julkisia puheita stand up -komiikan sukuisiksi performansseiksi, vaikkakin melko karkeiksi ja alatyylisiksi jopa stand up -komiikan mittapuilla. Sikäli kuin Donald Trumpin ja stand up -koomikoiden rinnastaminen on tietysti loukkaus stand up -komiikkaa kohtaan, en jatka vertailua tämän pidemmälle.

Stand up -koomikot, eli tutkimukseni kohteet, ovat nykypäivän julkisuuden näkyviä ammattilaisia, jotka ovat sisäistäneet meitä muita paremmin sen, että julkinen persoona on kallisarvoista kulttuurista valuuttaa, jota on syytä opetella esittämään tuottoisasti. Tuottoisimmin tätä persoonaa eli maskia julkisuudessa esittävät koomikot ovatkin viime aikoina edenneet taiteista toiselle keskeiselle julkisuuden areenalle, politiikkaan. Esimerkkejä politiikan piiriin siirtyneistä koomikoista voi löytää Yhdysvalloista, Islannista, Italiasta, Ukrainasta, ja Suomesta, jonka huhtikuisissa vaaleissa eduskuntapaikoista kilpailivat esimerkiksi pitkän linjan televisiokoomikko Pirkka-Pekka Petelius kuin myös entinen stand up -koomikko Lotta Backlund.

Stand up -komiikka on ainakin nettistriimausten ja koomikoiden palkkioiden perusteella tämän päivän suosituimpia suullisen sana- ja lavataiteen lajeja, jonka kirkkaimmat tähdet kuten Amy Schumer Yhdysvalloissa, Frankie Boyle Briteissä, Hannah Gadsby Australiassa tai esimerkiksi likka Kivi Suomessa, ovat nousseet varteenotettaviksi kulttuurikriitikoiksi ja julkisuuden kommentaattoreiksi. Viimeisimpänä palkkiollaan kohahdutti brittiläinen Ricky Gervais, joka kuittasi hieman yli tunnin mittaisesta Netflix-spesiaalistaan 40 miljoonaa dollaria ja sai ainakin suomalaisten koomikoiden keskuudessa osakseen myös kritiikkiä.

Samalla stand up on savuisten klubien, pubien ja kellarien tee-se-itse-taidetta, joka koomikoiden ja lajin harrastajien mukaan toimii parhaiten intiimissä, melko ahtaassa tilassa, jonne naurut jäävät "leijailemaan" eivätkä katoa yläilmoihin, kuten Joensuusta kotoisin oleva stand up -koomikko Aki Puolakka tätä ilmiötä kuvaa. Se on laji, jossa kuka tahansa voi ilmoittaa itsensä open mic -iltaan ja testata koomikon kykyjään oikean yleisön edessä. Se on myös laji, jossa omaa lavahahmoa ja tyyliä etsitään nimenomaan elävän yleisön kanssa. Aikamme yksilökeskeistä mutta myös stand upille luontaista demokraattista virettä kuvaa lajin epäsuorasti esittämä lupaus, että jokaisen meidän sisältä myös löytyisi tällainen yksilöllinen hahmo.

Lyhyesti sanoen stand up on tavattoman laaja ja monitahoinen nykykulttuurin ilmiö. Kun kuutisen vuotta sitten sain Suomen Kulttuurirahastolta kolmivuotisen rahoituksen aiheenani "Stand up -komiikka, genre ja performanssi", lajista ei ollut saatavilla aiempaa suomenkielistä tutkimusta joitain koomikoiden opinnäytetöitä ja populaariteoksia lukuun ottamatta - kansainvälistä tutkimustakin oli vielä melko vähän. En tuolloin tiennyt stand up -komiikasta Eddie Murphyn RAW:ta ja Bill Hicksin parhaita paloja lukuun ottamatta paljoakaan, mikä ei sikäli ollut epätavallinen lähtökohta, että juuri samaiset stand up -tallenteet, joskin VHS-muodossa, ovat olleet monille suomalaisille stand up -koomikoille ensikosketus lajiin.

Tuolloisissa romanttisissa mielikuvissani näin arvostetuimmat stand up -koomikot palavakatseisina saarnamies- tai -naishahmoina, jotka yhä uudestaan nousevat parrasvaloihin pilkatakseen yhteisöjensä arvoja ja asenteita vasten näiden kasvoja. Tämän jälkeen, huumorin huojentavan vaikutuksen laannuttua, yhteisön jäsenet voivat jälleen palata arkielämiinsä olemaan hyviä kansalaisia ja ihmisiä. Jotain tällaista löysinkin, mutta myös paljon muuta. 


\section{Yksilöllisyyden kaksinaisuus}

Kun nyt pysähdyn katsomaan, mitä onkaan tullut tehtyä, voin nähdä, että olen ollut liikkeellä suotuisaan aikaan. Stand up -komiikan tutkimus on viime vuosina räjähtänyt käsiin. Laji on vanginnut tutkijoiden mielenkiinnon kulttuurin ja median tutkimuksesta sosiologiaan ja antropologiaan, aina filosofiaa ja uskontotiedettä myöden. Oma tutkimukseni asettuu mielestäni luontevasti osaksi tätä tutkimuksen uusinta aaltoa. Sen laajempi anti tähän keskusteluun liittyy siihen, miten tästä Amerikan juutalaisten ja mustien 1900-luvun kuluessa luomasta esityslajista tuli 2000-luvun taitteessa maailmanlaajuisesti levinnyt poeettinen muoto, joka asettuu yhtä luontevasti niin Singaporeen kuin Suomeen, oman tutkimukseni keskeiselle etnografiselle kentälle. Tätä voisi pitää sitäkin hämmästyttävämpänä, kun suomalaisen suullisen kulttuurin stereotypian mukaan, lainatakseni tutkijoita Varis ja Blommaert (2015), "ellei ihmisellä ole mitään painavaa sanottavaa, hiljaisuus on aina small talkia parempi vaihtoehto ja löysä jutustelu saatetaan kokea epätoivottavana taparikkomuksena."

Stand upin poikkeuksellinen maailmanvalloitus, jonka mukana laji hiipi varovasti myös laman jälkeiseen Suomeen, ajoittuu netin ja nimenomaan Web 2.0:n eli sosiaalisen median aikakaudelle, jonka alustoilla monet meistäkin esittää joka päivä itseään. Stand up -koomikkoon verrannollisesti Facebook- tai Instagram-profiilini onkin yhtä lailla "minä itse" ja "minun itseni esitys" tai projektio. George Herbert Meadin, Erving Goffmanin, Judith Butlerin ja monien muiden jälkeen ymmärrämme entistä selkeämmin, ettei minulla itselläni ja itseni esityksellä ole merkittävää eroa. Vaikka näin olisikin, kiinnostavaa on esimerkiksi folkloristiikan ja kielitieteellisen antropologian näkökulmasta se, miten erilaiset viestintävälineet ja kontekstit, genret, niiden kielelliset rekisterit ja ideologiat, ynnä muut varioivat keskenään tuottaen uusia itsen performansseja ja sosiaalisia suhteita tutkijoiden teoretisoitavaksi.

Jos minun pitäisi tiivistää väitöskirjani yhteen virkkeeseen, voisin sanoa sen tiivistyvän stand up -komiikan mallintamiseen erilaisten kahtalaisuuksien ja kaksinaisuuksien leikiksi, joka parhaimmillaan osoittaa nämä kahtalaisuudet näennäisiksi, saman jatkumon eri vaiheiksi. Stand up on parrasvaloihin nostettua paskanjauhamista, mutta silti sen piirissä sanotaan kuultavan rehellisimpiä tilityksiä, mitä populaarikulttuurin puitteissa ylipäätään on mahdollista kuulla. Stand up on jokaista tavua myöden käsikirjoitettua ja harjoiteltua toistoa, mutta sen estetiikan ytimessä on spontaani välittömyys. Stand up on yleisö- ja yhteisölaji, jonka keskellä on yksilö. Tässä siis vain muutamia niistä vastakkaisuuksista, joita stand up peilaa ja joilla se leikkii.

Sikäli kuin esimerkiksi slovenialainen filosofi Alenka Zupančič (2008) on esittänyt, että komedia on kahtalaisuuksien taidetta, tutkimustani voisikin luonnehtia tämän peruspremissin kuvittamisena ja testaamisena ajankohtaisen lajin puitteissa.

Keskeisin stand upin kahtalaisuuksista koskee tietysti koomikon hahmoa itseään, niin kutsuttua stand up -koomikon lavapersoonaa, joka onkin kulttuurintutkijalle varsinainen avaamistaan odottava hunajapurkki - tai "matopurkki", kuten hankalasti teoretisoitavia kulttuuriobjekteja toisinaan nimitetään. Stand up -koomikon lavahahmo, jonka olemassaolon jotkut koomikot oireellisesti myös kieltävät, on sekä koomikko itse että jotain ylimääräistä. Mitä tuo "ylimääräistä" tarkkaan ottaen tarkoittaa, vaihtelee toki koomikosta toiseen, mutta jännite ihmisen itsensä ja hänen koomikkoroolinsa välillä pysyy. 
Tähän täydennyksenä sanoisin, että stand up -koomikot ovat yksilöllisiä persoonia, joiden pitää tuottaa itsestään samastuttava tyyppihahmo. Olen nimittänyt tätä liikettä yksilöllisyyden ja tyypillisyyden, tai, subjektiivisuuden ja objektiivisuuden väliseksi jatkumoksi, hahmoksi muuttumisen liikeradaksi. Jatkumon ensimmäisessä päässä näemme koomikon, joka esittää itseään mahdollisimman rehellisesti, paljastaa itsensä löytääkseen koomisen ja ristiriitaisen itsensä. Jatkumon toisessa päässä näemme stand up -koomikon, joka elävöittää kokonaisen kavalkadin erilaisia sosiaalisia ääniä, maalaa eteemme kohtauksia, joissa keskustelevat keskenään ihmiset, eläimet, abstraktit käsitteet ja objektit, kaikki peilaten toinen toisiaan.

Kuten Claude Lévi-Strauss olisi sanonut, binaaristen vastakkaisuuksien paradoksiset yhdistelmät ja artikulaatiot ovat monien kulttuurimuotojen kuten folkloren pysyvästi kuranttia peruskauraa. Stand up -komiikan kielelle käännettynä tämä voisi tarkoittaa, että kun kaikkein henkilökohtaisin on samalla jaettua, se on sitäkin tehokkaampaa.

Ja mikä olisikaan parempi esimerkki henkilökohtaisen ja jaetun yhtenevyydestä kuin huumorintaju itse, joka määrittää meitä moderneja länsimaisia ihmisiä sekä subjekteina että objekteina. Huumorintaju on jotain, jota pidämme omimpana itsenämme, mutta joka samalla yhdistää meidät kaltaisiimme ehkä vahvemmin kuin mikään muu. Tämä kahtalaisuus palautuu huumorin ja sen tajun käsitehistoriaan, siihen miten huumorin käsite muuttuu alkuaan keskiaikaisesta humoraali- eli ruumiinnesteiden opista - siis jostain, joka määritti ihmistä objektiivisesti - valistuksen myötä sisäsyntyiseksi kyvyksi, joka määrittää ihmistä subjektina ja persoonana.

Voisikin sanoa, että stand up -komiikassa heijastuvat nämä huumorintajun kulttuurihistorialliset kerrostumat omaleimaisella ja ainakin tutkijan huomion herättävällä tavalla. Kun vastaavia kahtalaisuuksia alkoi näkyä stand upissa laajemminkin, työni kiertyi niiden ympärille kuin magnetisoituna. Siitä myös tutkimuksen intiimiyden ja vastaväittäjältäni lainatun käsitteen eli "allegorisuuden", henkilökohtaisen ja yleisen risteymään viittaava nimi.

Tutkimuksen alaotsikko, itsevälittymisen poetiikka, antaa puolestaan vihjeen sanataiteesta ja sen tutkimukseen suuntautuneesta oppialasta, folkloristiikasta. Aloitin työni kartoittamalla stand up -komiikkaa melko perinteisin performanssi-folkloristisin menetelmin ja kysymyksenasetteluin. Halusin selvittää, mitkä ovat lajin keskeiset muodolliset ja funktionaaliset piirteet, miten kaavoittunut toisteisuus eli parallelismi jäsentää sen luonnetta vuorovaikutuksena ja miten näiden ominaisuuksien kautta voitaisiin argumentoida jotain stand upin etiikasta tai politiikasta. Työn edetessä laajensin satiirin moraaliin, stand up -keikkojen affektiivisuuteen, ja lajia läpitunkevan refleksiivisyyden eri tasoihin, mikä johtui osin kyllääntymisestä folkloristisiin asetelmiin, osin lisääntyneestä akateemisesta itsevarmuudesta.

Olen nimittänyt tutkimustani yhdistelmäksi performanssikeskeistä folkloristiikkaa, kielitieteellistä antropologiaa ja tieteidenvälisistä rajoista vähät piittaavaa kulttuurintutkimusta. Ihanteenani olen pitänyt ja pidän edelleen monilla eri skaaloilla samaan aikaan operoivaa tutkimusotetta, jossa viestinnällisen muodon, sisällön ja funktion kontekstiherkkä analyysi yhdistyisi poliittisesti edistykselliseen ja eettisesti kestävään sosiaali- ja kulttuuriteoriaan. 


\section{Välittömyys, autenttisuus, Toiseus}

Kulttuurintutkimuksen piirissä kuulee toisinaan ajatuksen, että populaarikulttuurin tai kansankulttuurin muodot toimisivat kulttuurissa ukkosenjohdattimina. Tämän ajatuksen mukaan nämä muodot kärjistäisivät olemassa olevia kulttuurisia tai yhteiskunnallisia tendenssejä, veisivät ne äärimmilleen ja nostaisivat ne näin yhteisen havainnoinnin ja arvioinnin piiriin. Tämä populaarikulttuurin tutkimuksen tärkeyttä puolustava argumentti on osa brittiläisen kulttuurintutkimuksen perinnettä, jonka mukaan kulttuurin ylhäiset kuin alhaisetkin kerrostumat voivat olla yhtä paljastavia niitä ympäröivien sosiaalisten ja kulttuuristen olosuhteiden kannalta.

Aloin vähitellen uskoa tätä väittämää tutkimukseni kuluessa. Stand upia leimaa autenttisuuden aura, ja koska parhain tapa tuottaa itsestään aito vaikutelma on olla välitön, stand upin kulmakiviä on myös välittömyyden ihanne. Stand up on toisen 2000-luvun menestyjän, tosi-tv:n, tavoin "konstruoitua välittömyyttä", mediatutkija Misha Kavkaa (2008) lainatakseni. Molempien lajien tuottamaan nautintoon liittyy keskeisesti sen kysymyksen yhteisöllinen puntaroiminen, onko esitetty "todellista" ja millä ehdoin. Mutta siinä missä tosi-tv pyrkii monesti hämärtämään toden ja keinotekoisen välistä rajaa, stand up -koomikot paljastavat kulissien takaiset toimintaperiaatteensa avoimesti.

En voi olla tässä yhteydessä palauttamatta mieleeni vanhaa Marcel Maussin laatimaa ja esimerkiksi Michael Taussigin sittemmin soveltamaa argumenttia, jonka mukaan taikuus ei ole tehokasta huijauksen vuoksi, vaan huijauksen paljastumisen vuoksi. Samoin kuin epäusko on edellytys taikuuden toimimiselle, uskon ja epäuskon välinen jännite on edellytys myös stand upista nauttimiselle. Sivumennen sanoen taikatemppujen, stand upin ja magian väliset yhteydet ovat yhä selvittämättä, mikä mahdollisia väitöksen jälkeisiä artikkeleita ajatellen muistiin merkittäköön.

Sikäli kuin autenttisuuden ja välittömyyden ihanteet ovat stand upin lausumattomia perusperiaatteita, normatiivisuuden ja Toiseuden teemat ovat olleet lajin identiteettipoliittista ydinmehua aina Lenny Brucen, Richard Pryorin ja Moms Mableyn tapaisista hahmoista alkaen. Tätä identiteettipolitiikkaa leimaa yhteiskunnallisten ongelmakohtien kommentoiminen yksilön, hänen kokemuksiin ja ruumiilliseen olemukseensa kytkeytyvien sosiaalisten aspektien kautta. Seuraavassa taidonnäyte New York -koomikko Hari Kondabolulta, jonka komiikan pysyviä aiheita ovat rasismi ja muut rakenteellisen sorron muodot.

[VIDEO: Hari Kondabolu: Warn Your Relatives. Netflix special. Katsottavissa kokonaan suoratoistopalvelu Netflixissä https://www.netflix.com/ watch/80213657]

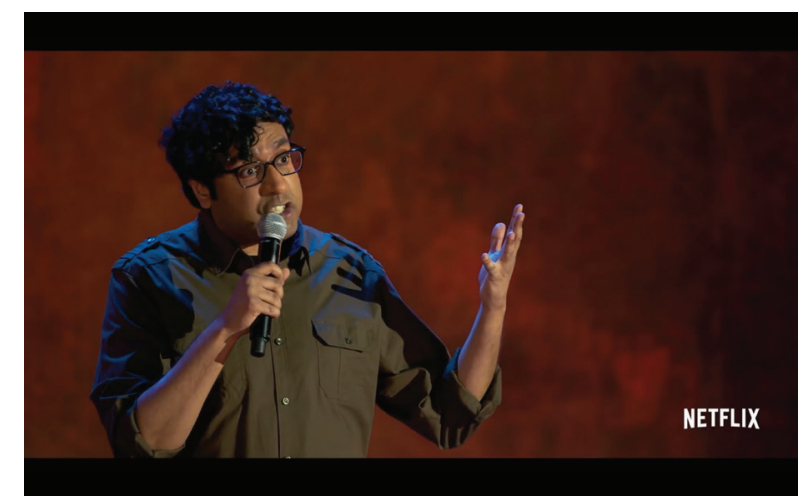

Jos stand up on urbaanin modernin ympäristön taidetta, kuten myös itse olen hiljalleen taipunut ajattelemaan, se on sitä siksi, että vain tällaisessa ympäristössä identiteetin sosiaaliset aspektit nousevat poliittisen mielenkiinnon ja sosiaalisen säätelyn alaiseksi. Stand up ei olisi voinut syntyä esimerkiksi 1800 -luvulla, koska sosiaalisen identiteetin aspekteja 
- rotua, uskontoa, luokkaa, sukupuolta ja seksuaalisuutta - ei vielä tuolloin ollut objektivoitu sellaisiksi henkilökohtaisen, arkisen ja poliittisen yhteen liittäviksi silloiksi kuin me ne nykyään ymmärrämme. Stand up nivoutuukin erityisen hyvin aikaamme, jossa esimerkiksi perinteisestä puoluepoliittisesta identifikaatiosta, jossa eri puolueet ovat tarjonneet kokonaisvaltaisempia viitekehyksiä, on siirrytty kohti spesifimmin ja yksilöllisemmin räätälöityä identifikaatiota, jota hallitsevat moraaliin, maailmankuvaan ja identiteettiin liittyvät arvot.

Koska jokainen aikakausi saa sellaiset populaarikulttuurin muodot kuin ansaitseekin, stand up -komiikka on aikamme kuva. Se kuva on samaan aikaan rosoinen, energinen, aggressiivinen, ennakkoluuloton, ennakkoluuloinen, nerokas, kaunainen, myötätuntoinen, kiusallinen, härski, hulvaton, ristiriitainen.

Lindfors, Antti. 2019. Intimately Allegorical: The Poetics of Self-Mediation in Stand-Up Comedy. Turun yliopiston julkaisuja - Annales universitatis turkuensis Sarja - ser. B osa tom. 478. Turku: Humaniora. https://www.utupub.fi/handle/10024/147073

\section{Lähteet}

Hall, Kira, Goldstein, Donna M. \& Ingram, Matthew Bruce. 2016. The hands of Donald Trump: Entertainment, gesture, spectacle. HAU: Journal of Ethnographic Theory 6(2), pp. 71-100.

Kavka, Misha. 2008. Reality Television, Affect and Intimacy: Reality Matters. Basingstoke: Palgrave Macmillan.

Kondabolu, Hari. 2018. Warn Your Relatives. Netflix special. Katsottu 6.6.2019. https://www. netflix.com/watch/80213657.

Rappoport, Leon. 2005. Punchlines. The Case for Ethnic, Racial, and Gender Humor. Westport, Conn.: Praeger Publishers.

Varis, Piia \& Blommaert, Jan. 2015. Conviviality and Collectives on Social Media: Virality, Memes, and New Social Structures. Multilingual Margins 2(1), pp. 31-45.

Zupančič, Alenka 2008. The Odd One In: On Comedy. Cambridge, Mass.: MIT Press. 